\title{
Measuring the Level of Economic Non-Freedom and Its Impact on the Economy of Russia
}

\author{
Sergey A. Surkov \\ International Institute of Management LINK (http://www.ou-link.ru/link/), Moscow, Russia \\ Email: context2002@yandex.ru, context2002@yahoo.com
}

Received April 25, 2013; revised May 25, 2013; accepted June 25, 2013

Copyright (C) 2013 Sergey A. Surkov. This is an open access article distributed under the Creative Commons Attribution License, which permits unrestricted use, distribution, and reproduction in any medium, provided the original work is properly cited.

\begin{abstract}
Work is devoted to studying of economy development regularities which are executed in Russia. A method for determining the level of economic non-freedom consists in obtaining the values of the relative profit when zero the number of employees the enterprise. 32 countries of the world have used published statistic data, for Russia, the specified methods have been added to two more. One is based on information from managers and business owners, and second on poll direct participants of economic processes. Averaging of these sizes allowed to define the level of economic nonfreedom in Russia as $48.9 \%$.
\end{abstract}

Keywords: Non-Freedom; Economic of Russia

\section{Introduction}

Mutually beneficial trade, exchange of technology, exchange of people, of achievements culture enriches people'life in all countries. This improves prospects of social development. Russia got rid of the command-administrative system. It has passed a long way of transformations and reformation of economy and it has achieved a great deal already. The integration of Russia in the global economic system in some areas has occurred. Numerous connections with the most various states were built. The participation of the Russian Federation in global trade and international division of labor significantly increased. It is assumed that the role of Russia in world economic activity will increase. It is difficult to imagine many important international projects, especially in the field of energy supply without Russia. This occurs despite of numerous attempts to find sources of alternative power supply, such as in Europe. Therefore, many countries are interested in the normal course of economic development in Russia. In the internal life of Russia a lot of things had changed. A new generation of entrepreneurs, managers, which feel confident in the market economy, have grown. Substantial "progress" has been made in the distribution of the property rights, though it is impossible to recognize fully orderly. Russia remains a country with nine sectors of the economy. The development of economy of Russia is substantially restrained by different limitations. The most important parts of them are diagnosed by the general term "economic non-freedom".

Economic non-freedom is a state of society, when any of its active members, aimed at creating positive values, can't fully realize its economic activities without affecting other's. Accordingly, in order to make it measurable, it is necessary to introduce the indicator of economic non-freedom, measured as a share of the opportunities of the individual, group of individuals, organizations and society at maximum free realization of their economic interests. Of course, the maximum is not reachable, it's a mirage, a utopia, but different countries differently progress on the path to this ideal.

Economic non-freedom is formed as a certain condition of public psychology, of conceptions, of views, of established behavior stereotypes, of opinions and judgements about the various society economic life phenomena. Legal support of economic development in this aspect always lagged behind the reality. It is caused on the current psycho-sociological state of society. Components of economic non-freedom, as shown by polls conducted by the author among 176 managers and company owners in Central Russia are corruption, extortion, nepotism, administrative barriers on a business way, counteraction to the free market relations from numerous supervising and control bodies, the interference of the criminal circles, mismanagement officials, tyranny of law authorities, incompatibility with reality economic practice, contradictions of the inert legislation, clan-corporative nature 
of the economy, negative attitude toward businessmen a part of the population and ruling elite, absence of formed public opinion, that supports the entrepreneurship. The specified components influence an actual level economic non-freedom differently. Besides, they are not equal and in public opinion. At the moment from the standpoint of public opinion the most important is the corruption component. Probably, when it will be eliminated or will be leveled, the most important will become the other component of economic non-freedom. It is difficult to predict which of the components will be leading. The end of the bribery can lead to the substantial change in the national culture, to the change in the social structure of the Russian society, to the change in personal social and economic status of many Russians. It is possible to assume that only component could be the public opinion. In case of a change of public opinion and with the support of society businessmen will be able more effectively to overcome numerous barriers in the way of their constructive activity.

Mass bribery is blocking economic growth. This is partly related to the fact that to the initial price of any product is added a "special tax". It includes bribes, kickbacks, and extortions from the side of authorities and criminal elements. This "tax" is replicated at every stage of production and product promotion. Accordingly, the final product turns out to be fabulously expensive. At the same time manufacturers are getting poverty-stricken, constantly being near the threshold of profitability. Such a scheme functioning of the Russian economy is a deadlocked. It uses unproductively national wealth, including human capital. The corruption scheme does not lead to the formation of the capacious domestic market. The funds in this market "pumped over" from the volumetric segments in the exclusive segments with the low volume, and they partially are frozen in the capital accumulated by the unjust way. These phenomena are trying to fight through administrative methods. Tighter legislation is carried out with simultaneous reduction of the freedom of entrepreneurial activity. The associativity of Russian market with the world market cannot be achieved within the framework of this model. It should be replaced by activities without paying bribe "tax".

\section{Literature Review}

In the world practice it is accepted to build the ratings of the countries according to the economic freedom index. Russian Federation constantly takes substantially adverse places in them. So, in the recently published report of the American Heritage Foundation Russia have put on not very honorable 146th [1]. The main components of economic non-freedom listed above do not help to create a positive attitude towards entrepreneurship.
S. Bavetta [2] reports of attempts to construct objecttive empirical indices of the extent of economic freedom enjoyed by countries on a world-wide basis.

C. R. Williamson and R. L. Mathers [3] include measures of culture and measures of economic institutions in growth equation.

Website Economic Freedom [4] point out that economic freedom is the key to greater opportunity and an improved quality of life. It analyzes five subcomponents to measure a country's level of economic freedom. These subcomponents include the size of government based on expenditures and taxes; the legal structure and its protecttion of property rights; access to sound money; freedom to trade internationally; and regulation of credit, labor, and business.

Website Free the World.com [5] emphasize that it is a necessary condition for democratic development. It liberates people from dependence on government in a planned economy, and allows them to make their own economic and political choices.

J. Gwartney and R. Lawson [6] point out that the key ingredients of economic freedom are: personal choice, voluntary exchange, freedom of competition and the protection of people and property. They indicate that the most recent edition of the EFW index contains 21 individual components. Within the five major areas, 21 components are incorporated into the index, but many of those components are themselves made up of several subcomponents.

Such a measure requires a lot of effort and money. For Russia and similar countries, the level of economic freedom is small, much smaller than it might seem from the outside, and it is advisable to use the concept of economic non-freedom.

The last survey VTsIOM (All-Russian Center for the Study of Public Opinion) [7] showed a positive result on this issue only 58.6 percent of those surveyed. According to Fund of "Public Opinion" 58 percent of respondents are positive towards entrepreneurs [8]. Center of Y. Levada [9] clarified this indicator, revealing that the level of unconditionally positive attitude is 45 percent. The above-mentioned elements of economic non-freedom lead to low economic activity Russian population. They cause a decline in business activity, create a sense of hopelessness among Russian citizens. The latter stimulates the larceny in companies and undeclared, "hidden" strikes in an uncontrolled scales, or work on the rules of the "Italian" strike. Low economic activity of population, and resulting consequences are blocking the activity of not only national but also foreign companies. Some of them have reduced their activities, and some at all went out or goes out of the Russian market. All this limits development of Russia. The analysis of the reasons for a high level economic non-freedom allows look for the 
ways of its overcoming that is why it is the important problem.

Economic non-freedom as a sign of low ethical culture in Russian society is a widely known fact.

For example, S. Schelin indicates that the fact that our system is based on clan structure, nepotism and state encouragement of the dullness, "is clear and for baby" [10]. However, the phenomenon of modern Russian life consists in the fact that the inadmissibility of the moral and ethical situation is clear for all segments of the population. Nevertheless, this does not lead to any concrete and effective measures to remove this situation. In part, this phenomenon is similar to the state of "delayed life" [11], that is also very typical of national practice. Persons, a groups, and even entire areas of persons are dreaming of a "good life" and aspire to it. Nevertheless, concrete actions to reach that goal delayed until "best times".

According to the organization The All-Russia AntiCorruption Public Reception "Clean hands", a corruption turnover of in Russia makes about 50 percent of gross domestic product [12]. This value practically corresponds to data of the World Bank, 48 percent of GDP [13]. The most corrupt is the sphere provision of public and municipal services, where a veiled corruption goes up to 90 percent of turnover. Businessmen complain that because of the corruption they lose about half of their income [14]. At same time, public opinion is inclined to the impossibility of eradicating corruption, at least under current conditions. The information channel Subscribe. ru (service VoxRu.Net) has addressed to the users of Russian Internet with a question on a possibility to win corruption [15]. The poll involved about 1900 people. Results of research showed that about 44 percent of the Russian Internet users believe that corruption amenable to eradication. 45 percent don't trust in such possibility, and 11 percent found it difficult to answer this question.

Using the problems of the Russian market and loopholes in the legal field, some foreign firms commit actions that can hardly be called well-posed. Traditionally, imported products are considered to be of higher quality than domestic. At the same time, they are more expensive, what provides substantial revenues from sales of these products in Russia. All the same, a number of foreign companies in Russia use the corruption schemes. They violate the country's laws and ethics of business at the same time. In the corruption scandals were involved the companies Daimler [16,17], IKEA [18], HewlettPackard [19] and others. More than 50 firms, including six leading German companies, signed a document under the name Corporate Ethics Initiative in an order that a bit to neutralize the consequences of scandals. It should promote to an ethically irreproachable conduct business in Russia. Nonetheless, experts estimate the chances of successful implementation of not sufficiently optimistic [20].

Thus, the economic non-freedom and the corruption as the most obvious and unacceptable manifestation of its, are causing a high public response.

It should be noted that corruption is one of the main but not the exclusive part of the economic non-freedom. This component has the most odious character, the higher it is, the greater the economic non-freedom. Experts relate it to $80 \%$ of the total value of the economic nonfreedom.

It negatively affects economic progress of Russia. The role of psycho-social factors in the efficiency of labor of its citizens is traditionally substantial.

The level of economic non-freedom has a negative impact on the economic life of society. It's not even the fact that entrepreneurs are forced to spend most of their profit for the purpose away from the needs of the industry, and the fact that people feel a sense of helplessness and futility of affirmative action, because what they have already achieved will be confiscated by the high level of economic non-freedom. According to experts, an increase of one percentage indicator of economic nonfreedom leads to a drop in GDP in Russia in half a percent. The ratio is specific to Russia, where a high proportion of public corporations in the GDP, and they subject to other laws.

\section{Methodology}

In the surveys used two types of interviews. The first is based on the use of a special questionnaire, answering questions which the respondent, among other things, done the answer to the question of what level it assesses the level of economic non-freedom in the country. The second type of interview is a questionnaire that included questions about the size of the organization, the area of its operations, the amount of the transaction and the number of participants in the transactions of the organization.

Below are various sources of information that used to obtain other data.

The purpose of this article is to find ways to determine the quantitative level of economic non-freedom in Russia and elsewhere. This will provide the basis for giving specific recommendations for its leveling.

\section{The Main Results}

The quantitative level of economic non-freedom related to the magnitude of the profits that the company spends on your own. In the post-industrial society each company on early stages of its activities fits into a certain market niche. Then it begins to form market under its aspirations. In the interests of the society firms need to achieve such 
position when each company is controlling the maximum part of its money flow. This part of their income, or, rather, profits, the company must spend on its development, modernization, creation of new products, services, information and technologies. An important part of activity every modern company is the public benefit which its work brings. The financial indexes of company must not only reflect successfulness of entrepreneurial activity but also the benefit to the society. Companies not publish information about using the revenue for development. Therefore, it may be hypothesized that this index may reflect the degree of entrepreneurial responsibility before the society. For carrying out researches was chosen the method based on studying of parameter, equal to the relation of revenue to profit. This parameter shows the profit margin, which used to increase the revenue. This indicator, or the ratio of revenue to profit, is considered as the level of "consciousness" of entrepreneurs.

That is, it is accepted as degree of use net profit to expand production, and respectively for increase revenue. This ratio should be presented in the form $\mathrm{Ln}(100 \mathrm{~V} / \mathrm{M})$, where V-gain or income, M-margin or profit. The method proposed above, applies to the study of indicators economic non-freedom. The analysis was conducted for those countries for which the direct collection of information on real projects and operations for any reason has been difficult or even impossible. Therefore, the analysis draws on information about the more general summary indicators such as annual earnings, annual profit and total employment for the eading firms in each country. These data are included in annual reports, respectively are being published, publicly available, for example, in the network Internet. Analysis is possible for all countries on the basis of the data found in a variety sources. This way was conducted the determination of necessary index of the level economical non-freedom for USA, Russia, China, India, Germany, Japan and other countries (altogether, for 51 countries).

Studies of the economic situation, in which can get reliable information, showed that it is appropriate to analyze the dependence in the coordinates " $\mathrm{Ln}(100 \mathrm{~V} / \mathrm{M})-$ $\mathrm{N}$ ", where $\mathrm{N}$-number of employees. Found that, in this case, the relation is linear, as seen, for example, on graphs of Figure 1, where shown examples with of the most obviously expressed dependencies.

The definition is based on the fact that value $\operatorname{Ln}(100$ $\mathrm{V} / \mathrm{M}$ ) for zero the number of employees, i.e., at intersecttion regression straight line axis of ordinates, is a measure economic non-freedom.

It follows from the fact that the company without employees does not have a profit, and the "residual" profit is the price that the firm must pay for the ability to function normally. If there is no employees, but the profit there is, then exactly this quantity and must be considered as the

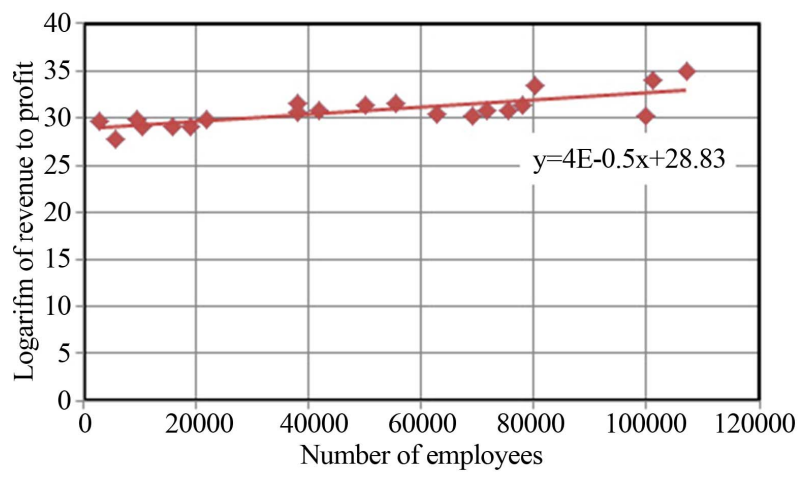

(a)

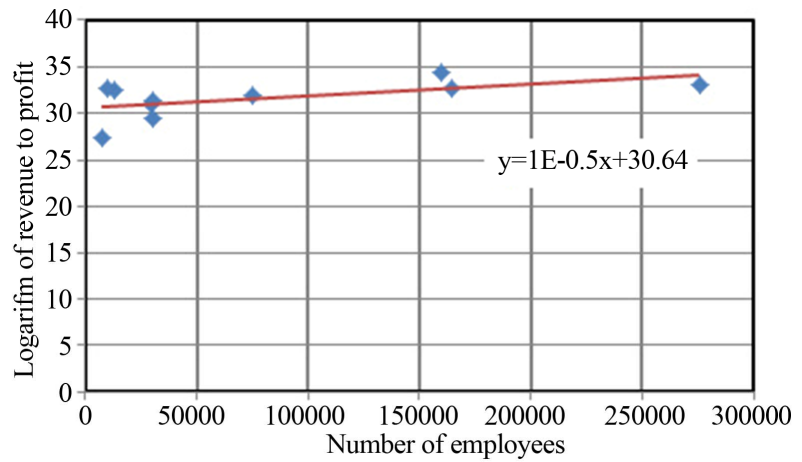

(b)

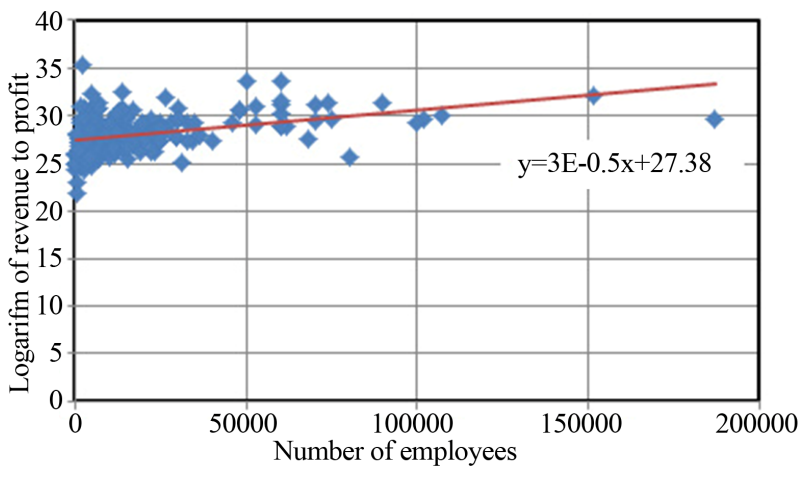

(c)

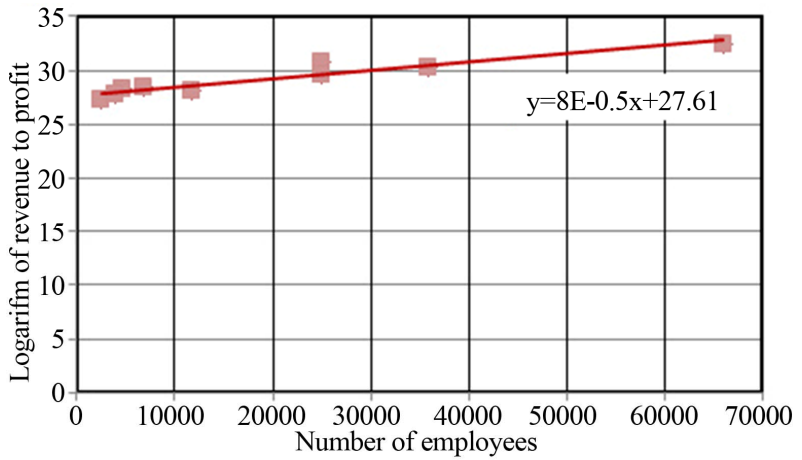

(d)

Figure 1. The dependence logarithm of revenue to profit from the personnel number for various companies and countries: (a) UK; (b) South Korea; (c) Russia; (d) Austria. 
level of illegal extortions and kickback from companies. This is due to the fact that, in order to start the functioning they must pay not less than that amount. The authorized capital does not have to do with it, because almost no effect on the actual movement of funds to organizations.

The coefficients of correlation for different countries vary from 0.31 to 0.95 , and are essential for all levels of significance that exceed 0.01 . There are several countries for which the data are insufficient, and the correlation coefficients for them are low. One of these countries was Venezuela, and had to exclude it from consideration at all. The reason for this was that all attempts to clarify data encountered significant distinctions in various sources of information on the activities of Venezuelan businesses. The number of enterprises, which published their data, is extremely small.

The published data refer to large firms with significant turnover, what necessary to consider. They can afford to hire experienced lawyers, and for these firms, some issues related to economic non-freedom, do not play a significant role. Accordingly, they do not have such a strong influence, as it happen for smaller business entities. Total analyzed data on 894 firms from 32 countries worldwide.

Types of economic behavior of enterprises vary for different countries, and, as expected, the regression lines for them have a different slope. In addition, there are different values of the absolute term in the regression equation, or, respectively, the level of economic nonfreedom for each country.

Two more methods were used to assess the level of economic non-freedom in Russia. The first method consisted of the direct collection of data about the level of margin (profitability) of Russian enterprises by polling the employees of these enterprises. The most different economic agents, from the small particular stores and the workshops to the important commercial firms and the industrial enterprises are selected as the sources of such data. At the list of analyzed organizations have been included food processing companies, trading companies, enterprises producing equipment, enterprises producing chemicals, organizations carrying out construction, organizations, providing various services on the market, including training and information services. In total data were obtained from 35 professionals and owners of firms from 46 projects. In each case, the respondents reported data about the average value of the bargain on their enterprise, about the level of the real profit, about quantity of people involved in the formation and closing of the bargains. All values were real, rather than evaluative. In addition, some data were taken from the literature.

They, as it was found, do not contradict the collected data. In particular, in an interview with the champion of the Turin Olympics, vice speaker of the Duma S. Žurova newspaper "Vzglayd" [21] was given the layout of the value of a bottle of vodka. She identified profit and selling price like 2.4 percent, and 89 rubles, respectively. According to a source of [22] average cost of 1 ton of fish production from the producer (regardless of breed) in 2008 was fixed at level of 27,500 rubles. In the retail, it amounted no less than 79,700 rubles.

All indicated data were brought together, and was built the graph of the dependence the ratio of gain and profit from a quantity of people, which participated in the transaction (Figure 2). The semi-log scale is used for a more clear representation of the data. The correlation coefficient for the dependence in Figure 2 totaled 0.625, which is essential for all significance levels exceeding 0.01 .

The comparatively high scatter associated with differences in organizational culture, work experience and term functioning of various organizations. Even so, the general trend of the resulting graph is visible. The regression equation has the form of $1.215 n+3.063$, where $\mathrm{n}$-number of people involved in the transaction.

The obtained equation of regression shows that at a zero quantity of people, which participate in the transacttion, the index of the ratio the revenue on profit, or more accurate, its logarithm, is not equal to zero, but is equal to 3.063. The value, obtained after conversion of the logarithm, is equal to 21.388 . For recalculate in the level of conditional "profit" is necessary to divide the value of harmonic mean from the revenue of all deals by this value. In this case, the calculations give a value of this parameter equal to 888.246. This is due to the use of inverse values. As a result we find that for lack of the transaction participants the profit level makes 41.5 percent. This magnitude can be accepted as excess of cost of products because of economic non-freedom, or level of economic non-freedom in Russia. A similar analysis can be carried out for to receive real value of level non-freedom other countries.

Poll of experts about level economic non-freedom in Russia was chosen as second analysis method. It was

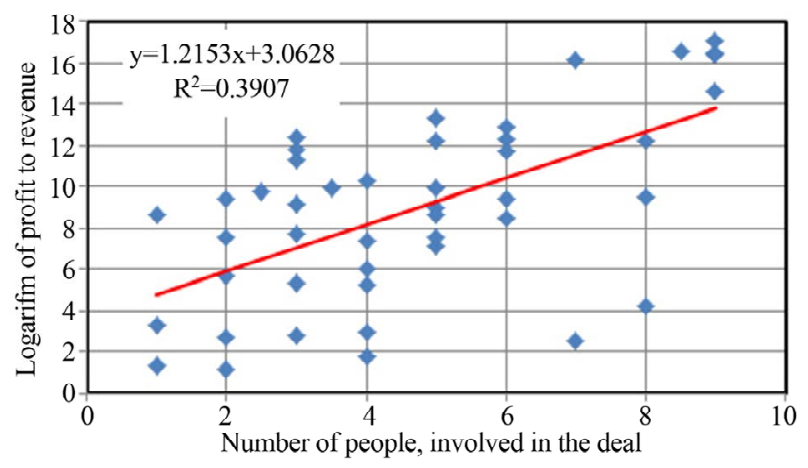

Figure 2. The graph of dependence the ratio profit to revenue on the number of people, involved in the deal. 
necessary to eliminate influence of ordinary consciousness and narrow-minded representations. They are largely shaped by the media, where this information is often served in a distorted form. Managers and owners of the enterprises, who directly conduct economic activities, have been involved In this regard, as experts. Their views are formed in accordance with the economic realities that surround them in their direct activities, and they are free from the influence of the media.

To get the data have been used four groups of referents. In the survey were participating entrepreneurs from Russia, Ukraine, USA, Germany and Kazakhstan. For elimination the influence of the groups sequence effect was used the mutual moving of the indicators where was conducted the poll. The results obtained in polls, were statistically indistinguishable. Therefore, it was possible to use them as united sampling from population. In addition, on the same subject have been interviewed more 167 experts-managers, so overall sample exceeded 200 people. Besides the question about the level of economic non-freedom in the questionnaire also were included questions about the level of poverty and about mutual influence of poverty and economic non-freedom. In a survey found that, according to respondents, the poverty rate in Russia amounts to 60.4 percent. This value is significantly different from the official figure for a living wage, which ranges from 13.1 percent [23] to 14.7 percent [24]. By comparing the different sources were obtained the data on the proportion of poor in Russia, that is, those who lives on low income. Change by years is shown in Figure 3.

From the data in Figure 3 we can see significant fluctuations in the level of poverty, with an overall trend of decline. These fluctuations can be partly explained by changes in calculation methods. The difference between official data and poll results in this study is probably due to the so-called "hidden" poverty. This kind of poverty means the inability to implement the simplest human wants. It is possible to assume that and the fluctuation of the officially fixed level of poverty occur, among others, under the effect of this factor. The Influence of economic

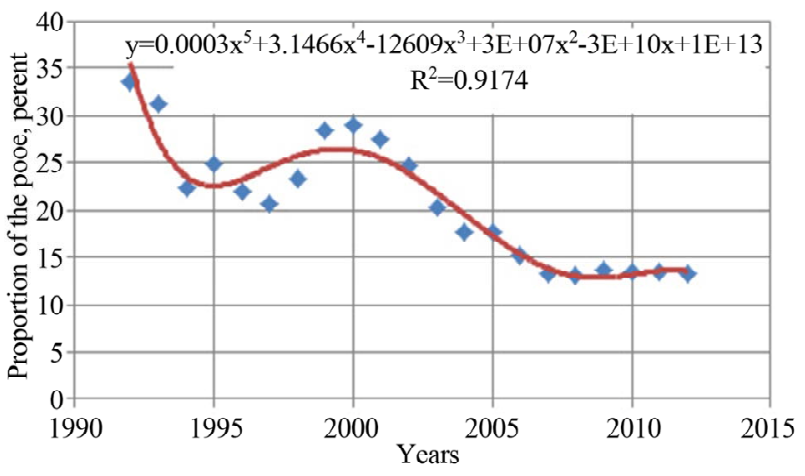

Figure 3. Change by years the proportion of poor in Russia. non-freedom on poverty is defined by level of 58.3 percent, and poverty on economic non-freedom-level of 49.6 percent. This discrepancy is substantial, which means the dominance of economic non-freedom in this pair. In other words, the economic non-freedom leads to poverty, not vice versa. Therefore, the fight against poverty must begin with the elimination of economic nonfreedom in the country.

The average rate of economic non-freedom, according to experts, made up 48.7 percent. The comparison of the obtained by three methods values of this index with the aid of the simplest criterion of Student made it possible to establish that the divergence is unessential. This means, that data are indiscernible, and is possible to use their average value, for example, an average arithmetic, equal 48.9 percent.

Probably for eliminate of corruption as a base and the main component of the economic non-freedom in Russia, it will be necessary to reduce the level of prices namely on the value of 48.9 percent. It will exclude possible sources of any requisitions and will lower possibilities bribery.

The level of economic non-freedom in $48.9 \%$ means that Russian entrepreneurs have to pay at least almost half of the profits in order to continue to exist only as an economic agent. This money does not get the economy and they are spent on consumption of other non-participants in the economic process.

Nevertheless, it is necessary to carry out in addition whole complex of measures. Global experience shows that it is possible. So, for example, China is trying to influence on bribe takers conscience, looks for new commodity markets and, the main thing, is using crisis to develop the country [25].

In general, a significant scatter the data of the level of economic freedom is typical for countries of the world. This is associated with the following features: with various national and economic traditions, with level of economic development, with the presence or absence of the national bourgeoisie, possession of mineral resources, with tradition of intellectual capital using, etc. If we compare the data obtained by the calculated way with the information presented on the site Heritage Foundation and The Wall Street Journal on this subject [26], then we can receive a graph, shown in Figure 4.

From the graph Figure 4 it is visible, that the values obtained by an offered method and expert data from a site are connected by linear dependence. The interrelation of these values characterizes the factor of correlation 0.71 , that is substantially to all significance levels, exceeding a level 0.01 . This confirms the validity of the proposed approach, which additionally allows determine the specific level of economic non-freedom. The equation of regression has the form $y=-0.326 x+72.63$, in 


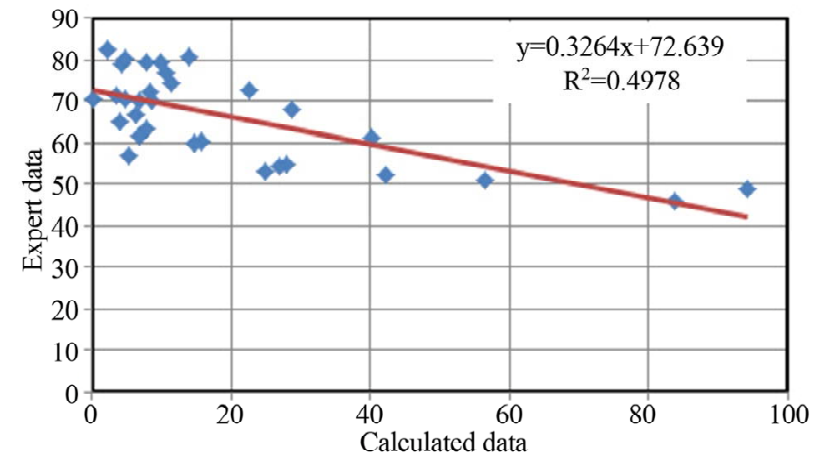

Figure 4. The comparison calculated and expert data in terms of the level economic non-freedom for various countries.

normalized form $y=-0.903 x+1.276$. Form of the equations shows that there is an understatement of the calculated index compared with expert index. The direction of the regression line is associated with different directions of the scales on the axes. However, it is necessary to remember, that for reception of considered two versions of a parameter economic non-freedom are used different factors. The part from them has the scattering owing to variety reasons of the social character. Therefore variability of data and their incomplete coordination are within acceptable levels. Thus, the hypothesis, put forward above, can be considered confirmed.

\section{Conclusions}

On the basis of the carried-out researches it is possible to draw the following conclusions:

1) Reducing the level of economic non-freedom, particularly corruption, probably, could be achieved by reducing the price by a certain amount, identified by the proposed method. For Russia it makes up 48.9 percent. Nevertheless, such decision, accepted by an administrative way, can cause an undesirable decreased level of economic freedom. Such an approach should be accompanied by a complex of administrative, economic, psychosociological measures.

2) It was established that dependences of the ratio of revenue to profits from the number of employees has linear character. The deviations from the straight lines characterizing the vast majority of the companies for each of the countries testify to either of deficiencies in the management of the company or about tax incorrectness in activity of the enterprises.

3) Existence of steady interrelation between the relation of revenue to profit, and of the company personnel number, testifies to existence of a certain general model of development firms, and financial mechanisms of their functioning. It consists in use not less than a certain share of profit on the expanded reproduction or enterprise expansion.
The study of the inverse relation of the profit to revenue allows us to obtain more complete data on the activities of firms and, in particular, multinational corporations. This gives the chance to analyze more fully economic processes in the global community.

\section{Acknowledgements}

I express my gratitude Elena Trofimova for assistance in obtaining and processing information and Nadine Kalinina for help in translating this article.

\section{REFERENCES}

[1] A. Kaledina, "Russia Recognized the Country's Economic Non-Freedom," 2009. http://izvestia.ru/news/344445

[2] S. Bavetta "Economic Freedom and Its Measurement," In: C. K. Rowley and F. Schneider, Eds., The Encyclopedia of Public Choice, Springer, England, 2003, pp. 485-487. http://ink.springer.com/book/10.1007/b108558/page/1

[3] C. R. Williamson and R. L. Mathers, "Economic Freedom, Culture, and Growth," 2009.

http://mercatus.org/sites/default/files/publication/Econom ic_Freedom_Culture_and_Growth.pdf

[4] http://www.economicfreedom.org/about/what-is-economi c-freedom/

[5] http://www.freetheworld.com/

[6] J. Gwartney and R. Lawson, "The Concept and Measurement of Economic Freedom," European Journal of Political Economy, Vol. 19, No. 3, 2003, pp. 405-430.

[7] Unequal Exchange: The Social Responsibility of Business and Its Recognition of the Russian Society," 2010. http://wciom.ru/index.php?id=268\&uid=13587

[8] G. Diligensky, "Business and Public Opinion," 2013. http://www.tolerance.ru/RP-business.php?PrPage=SMI

[9] O. Savelyev, "Attitude towards Entrepreneurs/Levada Center," 2008.

http://www.levada.ru/28-07-2008/otsenka-deyatelnosti-ro ssiiskikh-predprinimatelei

[10] S. Schelin, "Scoops of the XXI Century. Herald. Comments," 2010.

http://www.gazeta.ru/comments/2010/04/28_a 3358858.s html

[11] T. Ferris, "The 4 Hour Workweek," Crown Publishers, New York, 2007.

http://issuu.com/crown-publishing/docs/the-4-hour-work week-excerpt (accessed July 30, 2013).

[12] The Association of Russian Lawyers for Human Rights, "Corruption in Russia: The Annual Report of the Independent Public Reception of the All-Russian Anti-Corruption," Moscow, 2 July 2009-30 July 2010. http://s-pravdoy.ru/library2/sit-korrupcia/6012-2010-08-1 7-14-35-52.html

[13] Russian Federation, "A Bumpy Recovery: Russian Economic Report. Worldbank-Russia," The World Bank Country Office in Russia, Moscow, 2010. 
http://documents.worldbank.org/curated/en/2010/06/1482 1895/russian-economic-report

[14] E. Zibrova, "Corruption Grows Moscow," 2010. http://www.rbcdaily.ru/politics/562949978985449

[15] Information Channel Subscribe.ru, "Is It Possible to Eradicate Corruption in Russia?" 2010.

http://digest.subscribe.ru/economics/society/n316686511. html

[16] A. Sotnyk, "On the Strangeness of Business Ethics," 2010. http://www.svobodanews.ru/content/article/2022344.html

[17] P. Spelova, "Bribes Have Flown a Lot of Money," 2010. http://vz.ru/economy/2010/4/28/397219.html

[18] E. Belyakov and E. Panfilova, "Is It Possible to Live in Russia without Paying Bribes?" Komsomolskaya Pravda, Moscow, 2010. http://kp.ru/daily/24479.5/636749/

[19] D. Crawford and D. Searcey, "U.S. Joins H-P Bribery Investigation," 2010.

http://online.wsj.com/article/SB100014240527023046287 04575186151115576646.html

[20] Rambler Media Group Lenta. Ru, "The Germans Will Force Foreigner to Abandon of Bribery in Russia," 2010. http://lenta.ru/

[21] M. Shuvalova, "S. Zhurova 2010. Buy a Bottle I Did Not
Succeed," 2010.

http://vz.ru/economy/2010/3/11/383002.html

[22] RBC's Market research, "Retail Is in No Hurry to Lower Margins for Fish Products," 2009.

http://marketing.rbc.ru/news_research/13/04/2009/56294 9958591346.shtml

[23] "The Poverty Rate in Russia Fell to an Absolute Minimum". 2010

http://www.bfm.ru/news/2010/05/06/uroven-bednosti-v-r ossii-snizilsja-do-absoljutnogo-minimuma.html

[24] "The Poverty Rate in Russia Has Decreased by Almost 15\%," 2010. http://www.vesti.ru/doc.html?id=379945

[25] G. Zotov, "For Us, the Crisis-Hell, and for China - the Gift of God?" 2010

http://www.aif.ru/money/article/34163

[26] 2010 Index of Economic Freedom, "The Link between Economic Opportunity \& Prosperity," A Product of Heritage Foundation and the Wall Street Journal, 2012. http://www.docstoc.com/docs/83901302/2010-Index-ofeconoMIc-FReedoM 